\title{
Polymicrobial therapy induced nephrotoxicity: more is not always better
}

\author{
Ankit R. Mistry, Sapna D. Gupta, Supriya D. Malhotra*
}

Department of Pharmacology, Smt. NHL Municipal Medical College, Ahmedabad, Gujarat, India

Received: 22 February 2021

Accepted: 02 April 2021

\section{*Correspondence:}

Dr. Supriya D. Malhotra,

Email: supriyadmalhotra@gmail.com

Copyright: ( $)$ the author(s), publisher and licensee Medip Academy. This is an open-access article distributed under the terms of the Creative Commons Attribution Non-Commercial License, which permits unrestricted non-commercial use, distribution, and reproduction in any medium, provided the original work is properly cited.

\begin{abstract}
Polymicrobial induced nephrotoxicity (PIN) occurs more commonly in critically ill patients. Exposure to drugs often results in toxicity in kidney which represents a major control system maintaining homeostasis of body and thus is especially susceptible to xenobiotics. We present here an adverse drug reaction which is additive nephrotoxicity with combined antimicrobial use in critically ill patient. Blood urea and serum creatinine levels were raised much above the baseline after a fortnight of therapy. The suspected drugs were withdrawn leading to a gradual improvement and normalization of blood urea and serum creatinine levels This suggested a causal relationship which was possibly due to the administration of nephrotoxic antimicrobials. The present case highlights that critically ill patients on prolonged Polymicrobial therapy should be closely monitored, and dose increments should be made cautiously.
\end{abstract}

Keywords: Acute kidney injury, Critically ill, Xenobiotics, Serum trouh level, Nephrotoxic drugs, Polymicrobial induced nephrotoxicity

\section{INTRODUCTION}

In the era of modern medicine, patients are exposed to an expanding variety of drugs for diagnostic and therapeutic purposes. Unfortunately, some of these agents cause adverse drug effects linked with systemic toxicity, including impairment of renal function. ${ }^{1}$ There are drugspecific and patient-specific risk factors that influence the development of drug-related nephrotoxicity. Evaluation of nephrotoxicity through blood tests includes the measurements of blood urea nitrogen (BUN), concentration of serum creatinine, glomerular filtration rate and creatinine clearance. ${ }^{2}$ Nephrotoxicity can be defined as patients who developed acute renal failure. Acute renal failure can be defined as serum creatinine (SCr) increase by $0.5 \mathrm{mg} / \mathrm{dL}$ or increase by $50 \%$ from baseline. ${ }^{3}$ In a person without any kidney disease, serum creatinine is constant with a very small variability.
Nephrotoxicity is a common adverse effect of the clinically used Polymyxins (colistin, polymyxin B), aminoglycoside antibiotics, non-steroidal antiinflammatory drugs (NSAIDs), amphotericin B, contrast agents, and angiotensin converting enzyme inhibitors (ACEIs) in hospitalized patients. ${ }^{4}$ Aminoglycosides are well recognized nephrotoxins, causing a dose-dependent reduction in approximately $50 \%$ of kidney function in $10 \%-20 \%$ of patients. Gentamicin is recognized as the most nephrotoxic commonly used agent among this group, followed by Tobramycin and Amikacin. The Polymyxins (colistin and polymyxin B [PMB]) are old antibiotics that play a key part of against multidrug-resistant Gramnegative pathogens. Amphotericin B is currently used for the treatment of severe invasive fungal infections such as aspergillosis and candidiasis, primarily in immunocompromised patients. ${ }^{5}$ Drugs can cause nephrotoxicity by altering intraglomerular hemodynamic and decreasing GFR. 
We describe a case of reversible polymicrobial induced nephrotoxicity (PIN) with serum urea and creatinine levels exceeding in a young critically ill patient.

\section{CASE REPORT}

A 42-year-old male was brought to Emergency Medicine Department of a tertiary hospital with alleged history of fall from $5^{\text {th }}$ floor. On investigation, he had intraventricular hemorrhage with diffuse axonal injury, displaced fracture of left scapula, linear fracture of posterior shaft of $8^{\text {th }}, 9^{\text {th }}$, $10^{\text {th }}$ and $12^{\text {th }}$ ribs on right side, displaced fracture of transverse process of L1, L2 vertebra on right side and mild hemothorax on right side.

On admission the patient was unconscious and disoriented. Temperature was $99.8^{\circ} \mathrm{F}$, BP- $130 / 80 \mathrm{mmHg}$, RR- 16/min, pulse- $126 / \mathrm{min}$, pupil was bilateral reactive, muscle power was absent and planter reflex was mute. On arrival in emergency room, patient's tracheostomy tube was in situ. The patient tested negative for COVID-19 by RT-PCR. At that time, he was ventilated using VCV mode with tidal volume $500 \mathrm{ml}, \mathrm{PEEP}=5 \mathrm{~cm} \mathrm{H}_{2} \mathrm{O}, \mathrm{FiO}_{2}-40 \%$.

Table 1: His investigations on the day of admission were as follows.

\begin{tabular}{|ll|}
\hline Investigation parameter & Observed values \\
\hline Hb & $11.3 \mathrm{mg} / \mathrm{dl}$ \\
\hline WBC & $9.98 \mathrm{kU} / \mathrm{L}$ \\
\hline Platelets & $816 \mathrm{kU} / \mathrm{L}$ \\
\hline Urea & $40.7 \mathrm{mg} / \mathrm{dl}$ \\
\hline Creatinine & $0.97 \mathrm{mg} / \mathrm{dL}$ \\
\hline SGOT & $88 \mathrm{U} / \mathrm{L}$ \\
\hline SGPT & $110 \mathrm{U} / \mathrm{L}$ \\
\hline ALP & $205 \mathrm{U} / \mathrm{L}$ \\
\hline Albumin & $5.7 \mathrm{~g} / \mathrm{dl}$ \\
\hline PT & $16.4(12-16)$ \\
\hline APTT & 31.6 \\
\hline INR & $1.12(0.8-1.2)$ \\
\hline D-dimer & $3.55 \mu \mathrm{g} / \mathrm{ml}(<0.5)$ \\
\hline CRP & $12.0 \mathrm{mg} / \mathrm{L}(<5.0)$ \\
\hline Procalcitonin & $2.19 \mathrm{ng} / \mathrm{ml}$ \\
\hline
\end{tabular}

He was given Inj. Cefepime-Tazobactum 2.25 g every $12 \mathrm{~h}$, Inj. Vancomycin $1 \mathrm{gm}$ every $12 \mathrm{~h}$. Other drugs given to the patient included Tab.Levetiracetam 500mg, Tab.Valporate 500mg, Tab. Lacosamide 100mg, Tab. Clobazam 10mg, Tab.Cerebroprotein Hydrolysate 90mg and Neb Levosalbutamol-Ipratropium and Colistin. Patient was paralyzed using Atracurium and sedated with Midazolam and Fentanyl on the day of admission. On Day 3 his body temperature rose and WBC counts, Platelets and Procalcitonin level were increasing because of sepsis due to pneumonia. So he was administered Inj Gentamicin 80mg every 8 hrs, Inj Polymyxin B 5 Lacs IU every 8 h, Inj Fosphomycin every $12 \mathrm{hrs}$ and Tab Linezolid 600mg for broad spectrum coverage till report of tracheal culture was obtained. Culture report showed klebsiella pneumoniae and pseudomonas aeruginosa. In the course of admission his condition deteriorated and he was continued on ventilation using VCV mode with tidal volume $500 \mathrm{ml}$, $\mathrm{PEEP}=5 \mathrm{~cm} \mathrm{H} 2 \mathrm{O}, \mathrm{FiO} 2-40 \%$.

On Day-5, patient's Urea and S. Creatinine had more than doubled since admission (Figure 1). Urea levels further increased, measuring $131.6 \mathrm{mg} / \mathrm{dL}$ on 15thday (Figure:1) and S. Creatinine levels further increased, measuring 4.85 $\mathrm{mg} / \mathrm{dL}$ on $15^{\text {th }}$ day (Figure 2). Subsequently the levels of inflammatory markers like CRP (99.89 $\mathrm{mg} / \mathrm{L})$ and Procalcitonin $(26.78 \mathrm{ng} / \mathrm{ml})$ were also elevated.

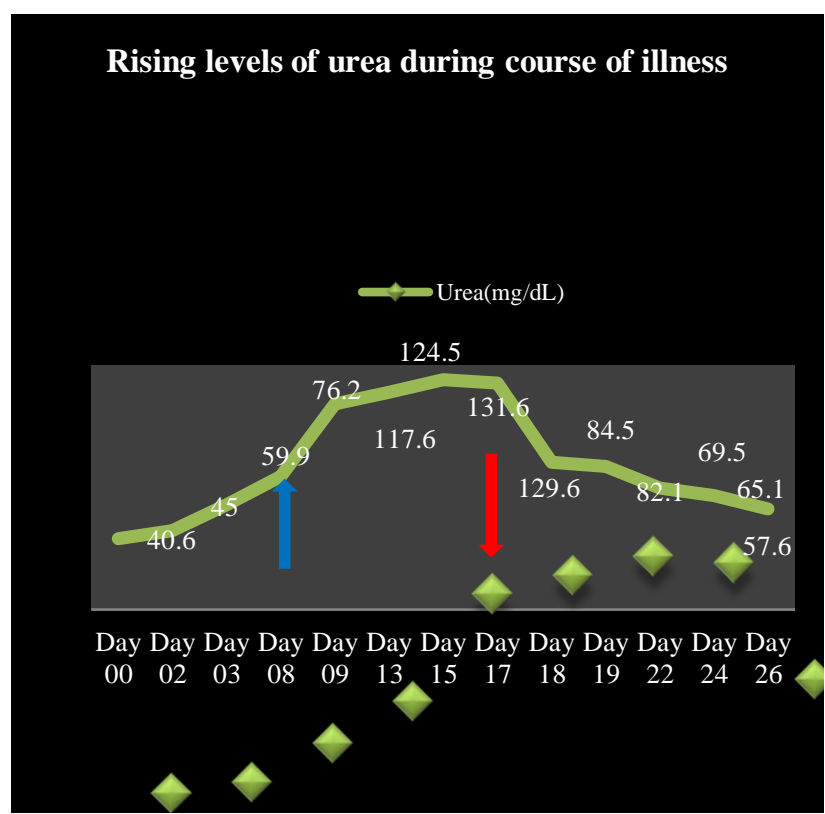

Figure 1: Patient's urea and S.creatinine had more than doubled since admission (blue arrow shows the beginning and red arrow show).

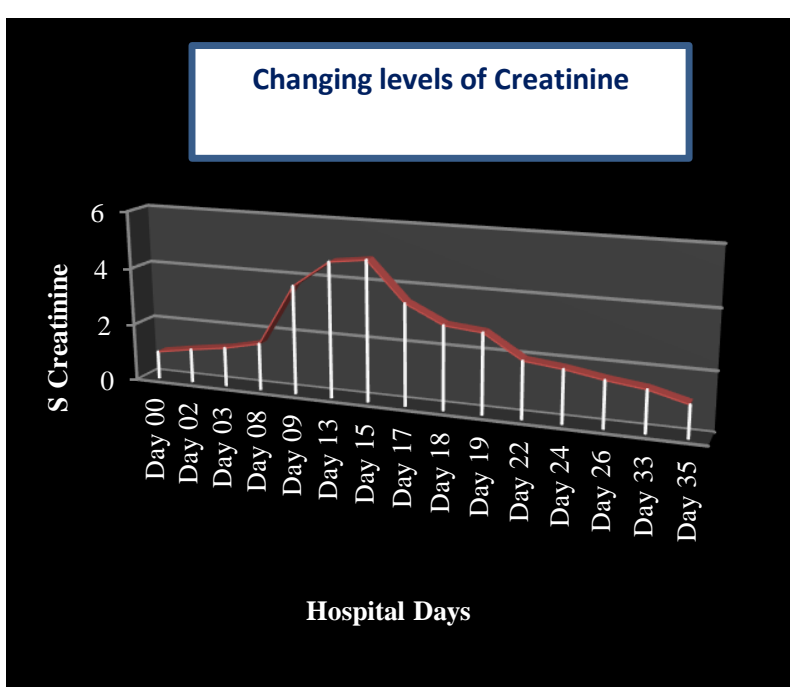

Figure 2: Elevations in S.creatinine after polymicrobial therapy and fall after withdrawl. 
Drug induced nephrotoxicity was suspected. Known nephrotoxins, Inj Gentamicin, Inj Polymyxin B and Inj Amphotericin B were withdrawn from his prescription. It was substituted by Inj Amoxycillin-Clavulanic acid 1.2gm every 12 hrs. Fever spike gradually subsided. Further evaluation for other causes of nephropathy was unrevealing including lack of history of hypertension and DM prior to, or during hospitalization

On day 17, patient's urea and S creatinine level began to decline back to baseline over the following three days after withdrawl of the nephrotoxic drugs. On $35^{\text {th }}$ day, S. creatinine was $1.11 \mathrm{mg} / \mathrm{dl}$. Due to patient's clinical condition, he was continued on supportive treatment. This case was reported to the closest ADR monitoring centre under pvpi via vigiflow with unique Id: IN-IPC 300502249 .

\section{DISCUSSION}

This case report was chosen to be reported as an adverse drug reaction due to nephrotoxic antimicrobial agents suggesting additive nephrotoxicity. ${ }^{6}$ This case describes a patient with no underlying comorbidities developing acute kidney injury secondary to drug induced nephropathy after receiving polymicrobial therapy.

The onset of renal failure from Aminoglycoside toxicity is usually slower, and the daily rise of serum creatinine tends to be lower than other causes of acute kidney injury characteristically taking 7-10 days to increase after initiation of Aminoglycoside therapy with associated aminoaciduria, glycosuria, hypomagnesemia, hypocalcemia, and hypokalemia. ${ }^{7}$

Table 2: The most commonly used Nephrotoxic Drugs. 5

\begin{tabular}{|lll|}
\hline Medication & Class & $\begin{array}{l}\text { Type of } \\
\text { damage }\end{array}$ \\
\hline Aminoglycosides & Antimicrobial & $\begin{array}{l}\text { Acute tubular } \\
\text { necrosis (ATN) }\end{array}$ \\
\hline Amphotericin B & Antifungal & $\begin{array}{l}\text { Acute tubular } \\
\text { necrosis (ATN) }\end{array}$ \\
\hline ACE/ARB & $\begin{array}{l}\text { Antihypertensiv } \\
\text { e }\end{array}$ & $\begin{array}{l}\text { Acute kidney } \\
\text { injury (AKI) }\end{array}$ \\
\hline Acyclovir & Antiviral & $\begin{array}{l}\text { Acute } \\
\text { interstitial } \\
\text { nephritis }\end{array}$ \\
\hline $\begin{array}{l}\text { Beta-lactam } \\
\text { antibiotics }\end{array}$ & Antimicrobial & $\begin{array}{l}\text { Acute tubular } \\
\text { necrosis (ATN) }\end{array}$ \\
\hline Vancomycin & Antimicrobial & $\begin{array}{l}\text { Acute } \\
\text { interstitial } \\
\text { nephritis }\end{array}$ \\
\hline Aspirin & Non-narcotic & $\begin{array}{l}\text { Chronic } \\
\text { interstitial } \\
\text { nephritis }\end{array}$ \\
\hline analgesic & Antineoplastic & $\begin{array}{l}\text { Chronic } \\
\text { interstitial } \\
\text { nephritis }\end{array}$ \\
\hline
\end{tabular}

Our patient developed acute kidney injury about the 5th day of treatment with polymicrobial therapy. Patient's Urea and S. Creatinine had risen above the baseline. We have reported a critically ill patient developing PIN after 5 days of therapy during course of admission.

In discussing drug-induced renal impairment, it is helpful to recall that renal function is a composite of several steps which includes renal arterial blood flow, glomerular filtration, tubular fluid formation, and exit of urine into the urogenital system. ${ }^{4}$ Drugs can impair renal function by interfering with any of these steps. Thus, one method of classification divides drug-induced nephrotoxicity into prerenal, intrarenal, or postrenal mechanisms. ${ }^{4}$ However, while many drugs have a single mechanism of injury, some classes of drugs possess multiple ways of inducing renal dysfunction as shown in Table $1 .^{7}$

Experimental studies revealed that Vancomycin induced nephropathy is due to oxidative stress which leads to tubular injury.6 The antifungal activity of Amphotericin B depends principally on its ability to bind ergosterol in the membrane of sensitive fungi. Azotemia occurs in $80 \%$ of patients who receive $\mathrm{C}$-AMB for deep mycoses. The lipid formulations are significantly less nephrotoxic than $\mathrm{C}$ AMB. Although permanent histological changes in renal tubules occur even during short courses of C-AMB. 8

The renal parameters of this patient improved spontaneously with a remarkable decrease in the blood urea and $\mathrm{S}$ creatinine levels, which conforms the association of nephrotoxicity with above mentioned antimicrobials. Therefore, clinicians must be aware of this adverse reaction and be cautious with dosing of antibiotics in patients with renal diseases and dosage must be adjusted carefully. Also combination of nephrotoxic antibiotics should be avoided if possible.

\section{CONCLUSION}

Critically ill patients on prolonged multiple antibiotics therapy may increase the risk for chronic kidney disease especially in some high-risk groups. The report here does not avert clinicians from prescribing antimicrobials agents but implies a message that polymicrobial induced nephrotoxicity can be prevented by use with cautions in dose increment for patients who are on long term therapy.

Funding: No funding sources

Conflict of interest: None declared

Ethical approval: Not required

\section{REFERENCES}

1. Nation RL, Rigatto MHP, Falci DR, Zavascki AP. Polymyxin Acute Kidney Injury: Dosing and Other Strategies to Reduce Toxicity. Antibiotics (Basel). 2019;8(1):24. 
2. Kim SY, Moon A. Drug-induced nephrotoxicity and its biomarkers. Biomol Ther (Seoul). 2012;20(3):26872 .

3. Ochoa PS, Terrell BT. A case of acute kidney injury with vancomycin and piperacillin/tazobactam. MOJ Clin Med Case Rep. 2017;7(5):297-9.

4. Fatemeh GS, Farahnak A. Drug-induced renal disorders. J Renal Inj Prev 2015;4(3): 57-60.

5. Shirali A, Pazhayattil GS. Drug-induced impairment of renal function. Int $\mathbf{J}$ Nephrol Renovascular Dis. 2014;457.

6. Oktem F, Arslan MK, Ozguner F, Candir O, Yilmaz $\mathrm{HR}$, Ciris M, et al. In vivo evidences suggesting the role of oxidative stress in pathogenesis of vancomycin induced nephrotoxicity: Protection by erdosteine. Toxicol. 2005;215:227-33.

7. Oliveira JF, Cipullo JP, Burdmann EA. Aminoglycoside nephrotoxicity. Braz J Cardiovasc Surg. 2006;21:444-52

8. P. David Rogers and Damian J. Krysan. Antifungal Agents. In: Brunton LB, Lazo JS, Parker KL, eds.Goodman \& Gilman's The Pharmacological Basis of Therapeutics. 13th ed. New York, NY: McGrawHill; 2018:1087-9.

Cite this article as: Mistry AR, Gupta SD, Malhotra SD. Polymicrobial therapy induced nephrotoxicity: more is not always better. Int $\mathrm{J}$ Basic Clin Pharmacol 2021;10:571-5. 